\title{
Klebsiella pneumoniae liver abscess: a case report
}

\author{
P. N. S. Premathilake*, W. K. S. Kularatne, J. P. K. Jayathilake and S. D. N. Senadhira
}

\begin{abstract}
Background: Liver abscess has formerly been a polymicrobial infection. Currently, liver abscess due to Klebsiella pneumoniae is increasingly reported, predominantly in Southeast Asia for unknown reasons. Liver abscess due to Klebsiella pneumonia has never been previously reported in Sri Lanka.

Case presentation: A 63-year-old Sinhalese man with diabetes mellitus and a poor glycemic control presented with fever, loose stools, and loss of appetite of 1 week's duration. An examination was unremarkable apart from a mild non-tender hepatomegaly. Investigations indicated a septic process with neutrophil leukocytosis,

thrombocytopenia, and raised inflammatory markers with acute kidney injury. Sonography of his abdomen revealed a large liver abscess with two blood cultures positive for Klebsiella pneumoniae. He made a complete recovery following aspiration of the abscess and treatment with intravenously administered ceftriaxone.

Conclusion: Liver abscess due to Klebsiella pneumoniae is an emerging infection and most commonly reported from Southeast Asia. In Sri Lanka, further studies are necessary to understand the epidemiology and modes of spread. Furthermore, a high index of suspicion is essential as early detection is the key to successful treatment and prevention of complications.
\end{abstract}

Keywords: Liver abscess, Klebsiella pneumoniae, Sri Lanka

\section{Introduction}

Liver abscess due to Klebsiella pneumoniae is an emerging infection worldwide with predominance in Southeast Asia. The virulent strains $\mathrm{K} 1$ and $\mathrm{K} 2$ are recognized to cause a new invasive syndrome with metastatic infection $[1,2]$. Diabetes mellitus is a significant risk factor for the development of Klebsiella pneumoniae liver abscess (KLA). Poor glycemic control results in a worse prognosis and complications including sight-threatening endophthalmitis [3]. We report the first case of KLA in Sri Lanka.

\section{Case presentation}

A 63-year-old Sinhalese man with diabetes mellitus of 8 years' duration presented with fever, loose stools, and loss of appetite of 1 week's duration. He was on diet control for diabetes with poor glycemic control and was not on a proper follow up. On admission he was ill and febrile. An abdominal examination revealed hepatomegaly, $2 \mathrm{~cm}$ from right costal margin, which was

\footnotetext{
* Correspondence: nspremathilake@gmail.com

Department of Medicine, Teaching Hospital Kandy, Kandy, Sri Lanka
}

non-tender. Other systemic examination was unremarkable. An ophthalmoscope examination revealed non-proliferative diabetic retinopathy. A full blood count revealed white cell count of $18 \times 10^{9} / \mathrm{L}$ with neutrophil predominance. His hemoglobin was $12.2 \mathrm{~g} / \mathrm{dL}$ and platelet count was $256 \times 10^{9} / \mathrm{L}$ initially and dropped up to $9.8 \mathrm{~g} / \mathrm{dl}$ and $63 \times 10^{9} / \mathrm{L}$, respectively. Blood film showed severe bacterial infection with sepsis and features suggestive of disseminated intravascular coagulation (DIC). A coagulation profile showed international normalized ratio of 1.7 and activated partial thromboplastin time of 37 seconds. Erythrocyte sedimentation rate was $75 \mathrm{~mm} /$ first hour. His C-reactive protein level was $197 \mathrm{mg} / \mathrm{dL}$ and his procalcitonin level was $59.9 \mathrm{ng} /$ L. Consecutive blood cultures were positive for Klebsiella pneumoniae after 9 and 13 hours. The strain was sensitive to imipenem, meropenem, ceftriaxone, amikacin, and ciprofloxacin. A chest radiograph was normal. Retroviral screening was negative. His fasting blood sugar level was $212 \mathrm{mg} / \mathrm{dl}$. A urine full report showed proteinuria $(++)$ with $3-5$ pus cells per high power field and the urine culture was negative. Stool examination 
was negative for amoebae, ova, or cysts. His initial serum creatinine level was 134 microgram/L and increased up to $647 \mathrm{microgram} / \mathrm{L}$ reflecting acute kidney injury. His urine output was satisfactory throughout the course. Serum potassium went up to $6.1 \mathrm{mmol} / \mathrm{L}$ and was managed medically. An ultrasound scan of his abdomen revealed a large ill-defined hypoechoic lesion suggestive of a liver abscess in the right lobe of his liver, at segments VII and VIII, measuring $8 \times 6 \times 5.5 \mathrm{~cm}$ in size (Fig. 1). Lower gastrointestinal endoscopy was normal. The abscess was aspirated once by the interventional radiology team under ultrasound guidance yielding $100 \mathrm{ml}$ of thick pus. He was treated with intravenously administered ceftriaxone for 2 weeks and a marked clinical and biochemical improvement was seen. His serum creatinine returned to upper normal limit following resolution of sepsis. A repeat ultrasonography performed at completion of intravenous antibiotic therapy revealed resolving abscess in segment VIII of his liver measuring $5 \times 4 \times 3.2 \mathrm{~cm}$. As there was considerable clinical and biochemical improvement, he was discharged with a further course of orally administered cefixime and did not require further aspirations.

\section{Discussion}

A liver abscess is a potentially life-threatening infection. Common causes predisposing to occurrence of liver abscess include biliary disease, malignancies of gastrointestinal tract, and pylephlebitis [4]. It is commonly a polymicrobial infection and the common causative organisms well documented in the literature include Escherichia coli, streptococci, Enterobacteriaceae, and anaerobes [5-7]. But currently there is an emerging trend of primary liver abscess caused by Klebsiella pneumonia.

Klebsiella pneumoniae is a Gram-negative bacillus belonging to the genus Klebsiella. It is an important

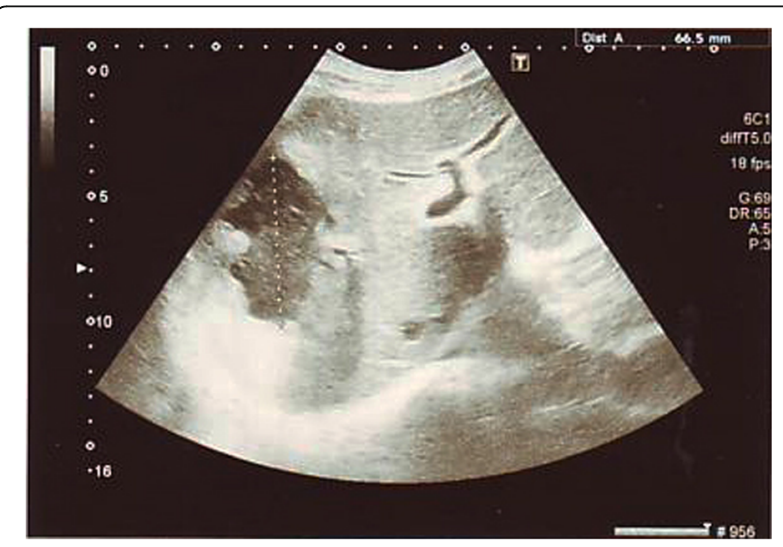

Fig. 1 Liver abscess in the right lobe of the liver nosocomial pathogen and is mostly associated with respiratory and urinary tract infections [8].

Primary liver abscess due to Klebsiella pneumoniae was first described in the literature in 1986 in Taiwan [9]. A recent alarming incidence of a new syndrome due to $\mathrm{K} 1$ and $\mathrm{K} 2$ serotypes of Klebsiella pneumoniae is reported, mainly in Taiwan [1,2]. The cause for the predominance of cases in Southeast Asia is not currently understood and a genetic predisposition is still not proven. However a high fecal carriage of virulent K1 Klebsiella pneumoniae ST23 strains was demonstrated in individuals of Southeast Asia and may explain the higher incidence [10]. Intestinal colonization with virulent strains has been shown to be highly associated with development of KLA [11].

This genotype, which is strongly associated with highly invasive disease in Taiwan, has also been reported in three continents denoting its widespread geographic existence [12]. KLA is currently recognized as an emerging infection and an important cause of sight-threatening endophthalmitis in a number of countries worldwide $[2,13]$.

Patients with diabetes are more prone to develop KLA and related septicemic complications. Also, regardless of etiology, they have longer periods of fever after treatment and prolonged hospital stay [14, 15]. Poor glycemic control impairs the phagocytosis of K1/K2 Klebsiella pneumoniae. Thus poorly controlled diabetes increases the susceptibility to K1/K2 Klebsiella pneumoniae infections and related liver abscess and complicated endophthalmitis [3]. Also KLA has been shown to be strongly associated with colorectal cancer, particularly in the sigmoid colon and rectum, in the Eastern Asian male population [16].

The rmpA gene of Klebsiella pneumoniae, Acute Physiologic and Chronic Health Evaluation (APACHE) II score $\geq 2$, and septic shock were found to be statistically significant predictors of metastatic infection due to KLA. The predictors of mortality due to KLA include metastatic infection, severity of infection, septic shock, acute respiratory failure, and gas formation in radiography [17]. Molecular analysis and virulence studies have revealed phagocytic resistance associated with K1 serotype and hypervirulence associated with the aerobactin gene [18].

Numerous extrahepatic complications of KLA reported in the literature include meningitis, bacteremia with multiple metastatic abscess formations, epidural abscess formation, necrotizing fasciitis, septic arthritis, and septic pulmonary embolism [19-22]. Of these, sight-threatening endophthalmitis has been commonly reported [23]. Diabetes is a significant risk factor for development of endophthalmitis and predicts a poor visual outcome [24]. 
Diagnosis of KLA is made based on culture evidence and radiography. On computed tomography the features that suggest KLA include single abscess, unilobar (commonly right) involvement, and solid or multiloculated appearance [25].

Third generation cephalosporins are the preferred choice of treatment in KLA. Pigtail catheter drainage is shown to be protective against metastatic infection and mortality. Treatment with first generation cephalosporins and percutaneous drainage has been found to be associated with low mortality rates, metastatic infection and complications, showing comparable rates to treatment with third generation cephalosporins [17].

In Sri Lanka, one case of a 14-year-old girl has been previously reported with pyogenic liver abscess due to Klebsiella species [26]. However, to the best of our knowledge, this is the first reported case of Klebsiella pneumoniae causing pyogenic liver abscess in Sri Lanka.

\section{Conclusion}

Considering the reported rise of KLA according to recent literature and its preponderance to occur in Southeast Asian countries, it is worthwhile to suspect Klebsiella pneumoniae as an etiological agent in cases of liver abscess in Sri Lanka. Early clinical suspicion mainly in patients with diabetes can lead to early intervention, institution of appropriate therapy, and minimize complications.

\section{Abbreviations}

APACHE: Acute Physiologic and Chronic Health Evaluation; DIC: Disseminated intravascular coagulation; KLA: Klebsiella pneumoniae liver abscess

\section{Acknowledgements}

We appreciate Dr BMDB Basnayake, who provided medical writing services.

\section{Authors' contributions}

WKSK, SDNS, and JPKJ made the clinical diagnosis and supervised the manuscript drafting. PNSP wrote the first draft of the manuscript and reviewed the literature. WKSK, SDNS, JPKJ, and PNSP were involved in the management of the patient. All authors read and approved the final manuscript.

\section{Authors' information}

WKSK (MBBS, MD, MRCP, FRCP, FCCP), consultant physician; SDNS (MBBS, $M D)$ and JPKJ (MBBS, MD), Senior registrars in Medicine, work at the Teaching Hospital Kandy, Sri Lanka. PNSP is a medical registrar at the Teaching Hospital Kandy, Sri Lanka.

\section{Ethics approval and consent to participate}

Not applicable.

\section{Consent for publication}

Written informed consent was obtained from the patient for publication of this case report and any accompanying images. A copy of the written consent is available for review by the Editor-in-Chief of this journal.

\section{Competing interests}

The authors declare that they have no competing interests.

\section{Publisher's Note}

Springer Nature remains neutral with regard to jurisdictional claims in published maps and institutional affiliations.

Received: 10 January 2018 Accepted: 12 November 2018

Published online: 13 December 2018

\section{References}

1. Siu LK, Yeh KM, Lin JC, Fung CP, Chang FY. Klebsiella pneumoniae liver abscess: a new invasive syndrome. Lancet Infect Dis. 2012;12(11):881-7.

2. Lederman ER, Crum NF. Pyogenic liver abscess with a focus on Klebsiella pneumoniae as a primary pathogen: an emerging disease with unique clinical characteristics. Am J Gastroenterol. 2005;100(2):322-31.

3. Lin JC, Siu LK, Fung CP, Tsou HH, Wang JJ, Chen CT, et al. Impaired phagocytosis of capsular serotypes K1 or K2 Klebsiella pneumoniae in type 2 diabetes mellitus patients with poor glycemic control. J Clin Endocrinol Metab. 2006;91(8):3084-7.

4. Seeto RK, Rockey DC. Pyogenic liver abscess changes in etiology, management, and outcome. Medicine. 1996;75(2):99-113.

5. Brook I, Frazier EH. Microbiology of liver and spleen abscesses. J Med Microbiol. 1998;47(12):1075-80.

6. Moore-Gillon JC, Eykyn SJ, Phillips I. Microbiology of pyogenic liver abscess. Br Med J (Clin Res Ed). 1981;283(6295):819-21.

7. Rubin RH, Swartz MN, Malt R. Hepatic abscess: changes in clinical, bacteriologic and therapeutic aspects. Am J Med. 1974;57(4):601-10.

8. Podschun R, Ullmann U. Klebsiella spp. as nosocomial pathogens: epidemiology, taxonomy, typing methods, and pathogenicity factors. Clin Microbiol Rev. 1998;11(4):589-603.

9. Liu YC, Cheng DL, Lin CL. Klebsiella pneumoniae liver abscess associated with septic endophthalmitis. Arch Intern Med. 1986;146(10):1913-6.

10. Chung DR, Lee H, Park MH, Jung SI, Chang HH, Kim YS, et al. Fecal carriage of serotype K1 Klebsiella pneumoniae ST23 strains closely related to liver abscess isolates in Koreans living in Korea. Eur J Clin Microbiol Infect Dis. 2012;31(4):481-6.

11. Fung $C P$, Lin $Y T$, Lin JC, Chen TL, Yeh KM, Chang FY, et al. Klebsiella pneumoniae in gastrointestinal tract and pyogenic liver abscess. Emerg Infect Dis. 2012:18(8):1322.

12. Turton JF, Englender H, Gabriel SN, Turton SE, Kaufmann ME, Pitt TL. Genetically similar isolates of Klebsiella pneumoniae serotype K1 causing liver abscesses in three continents. J Med Microbiol. 2007;56(5):593-7.

13. Lindstrom ST, Healey PR, Chen SC. Metastatic septic endophthalmitis complicating pyogenic liver abscess caused by Klebsiella pneumoniae. Intern Med J. 1997;27(1):77-8.

14. Wang JH, Liu YC, Lee SS, Yen MY, Chen YS, Wang JH, et al. Primary liver abscess due to Klebsiella pneumoniae in Taiwan. Clin Infect Dis. 1998;26(6): $1434-8$

15. Chang FY, Chou MY. Comparison of pyogenic liver abscesses caused by Klebsiella pneumoniae and non-K. pneumoniae pathogens. J Formos Med Assoc. 1995;94(5):232-7.

16. Qu K, Liu C, Wang ZX, Tian F, Wei JC, Tai MH, et al. Pyogenic liver abscesses associated with nonmetastatic colorectal cancers: an increasing problem in Eastern Asia. World J Gastroenterol. 2012:18(23):2948.

17. Lee SS, Chen YS, Tsai HC, Wann SR, Lin HH, Huang CK, et al. Predictors of septic metastatic infection and mortality among patients with Klebsiella pneumoniae liver abscess. Clin Infect Dis. 2008;47(5):642-50.

18. Siu LK, Fung CP, Chang FY, Lee N, Yeh KM, Koh TH, et al. Molecular typing and virulence analysis of serotype K1 Klebsiella pneumoniae strains isolated from liver abscess patients and stool samples from noninfectious subjects in Hong Kong, Singapore, and Taiwan. J Clin Microbiol. 2011;49(11):3761-5.

19. Chang WN, Huang CR, Lu CH, Chien CC. Adult Klebsiella pneumoniae meningitis in Taiwan: an overview. Acta Neurol Taiwanica. 2012;21(2):87-96.

20. Hsieh MJ, Lu TC, Ma MH, Wang HP, Chen SC. Unrecognized cervical spinal epidural abscess associated with metastatic Klebsiella pneumoniae bacteremia and liver abscess in nondiabetic patients. Diagn Microbiol Infect Dis. 2009:65(1):65-8.

21. Hu BS, Lau YJ, Shi ZY, Lin YH. Necrotizing fasciitis associated with Klebsiella pneumoniae liver abscess. Clin Infect Dis. 1999:29(5):1360-1.

22. Kohler JE, Hutchens MP, Sadow PM, Modi BP, Tavakkolizadeh A, Gates JD. Klebsiella pneumoniae necrotizing fasciitis and septic arthritis: an appearance in the Western hemisphere. Surg Infect. 2007;8(2):227-32. 
23. Abdul-Hamid A, Bailey SJ. Klebsiella pneumoniae liver abscess and endophthalmitis. BMJ Case Rep. 2013;2013:bcr2013008690.

24. Sheu SJ, Kung YH, Wu TT, Chang FP, Horng YH. Risk factors for endogenous endophthalmitis secondary to Klebsiella pneumoniae liver abscess: 20-year experience in Southern Taiwan. Retina. 2011;31(10):2026-31.

25. Alsaif HS, Venkatesh SK, Chan DS, Archuleta S. CT appearance of pyogenic liver abscesses caused by Klebsiella pneumoniae. Radiology. 2011;260(1):129-38.

26. De Silva GN, Pathirana K. Pyogenic liver abscess. Sri Lanka J Child Health. 2009;30(4):110.

Ready to submit your research? Choose BMC and benefit from:

- fast, convenient online submission

- thorough peer review by experienced researchers in your field

- rapid publication on acceptance

- support for research data, including large and complex data types

- gold Open Access which fosters wider collaboration and increased citations

- maximum visibility for your research: over $100 \mathrm{M}$ website views per year

At $\mathrm{BMC}$, research is always in progress.

Learn more biomedcentral.com/submissions 